\title{
Antiproliferative and Apoptotic Induction of Allicin in Human Lung Cancer Cell Lines
}

\author{
Zeenath Vadakkenchery Mohammed Hussain, Santhy Kumaran Sivanandhan* \\ Department of Zoology, Avinashilingam Institute of Higher Education for Women, Coimbatore, Tamil Nadu, INDIA.
}

\begin{abstract}
Background: The study relied on exploring the anticancer effects of allicin and the experimental parameters to scientifically prove its potential as a natural anticancer agent, condiment and dietary supplement present in several Allium plant varieties. Materials and Methods: In the current investigation, the efficiency of allicin was checked for its antiproliferative and apoptosis-prompting potential in the human lung cancer cell lines A549. Results: The inhibitory concentration $\left(\mathrm{IC}_{50}\right)$ of allicin was $28 \mu \mathrm{M}$ against $\mathrm{A} 549$ cell lines. Marked apoptotic morphological changes and DNA damage were observed and visualized by standard staining. Effects of allicin on the cell cycle were determined using flow cytometry. Allicin induced apoptosis of A549 cells $24 \mathrm{~h}$ after treatment and decreased the number of in S-phase and indicating cell cycle arrest at G1. These results suggest that allicin killed cancer cells through apoptosis and cell cycle arrest. Further, protein and gene expressions were analyzed by western blot and RT-PCR analysis. Our results showed that, the allicin instigated apoptotic cell death in through intrinsic pathways by the activation of Caspase family proteins.
\end{abstract}

Key words: Allicin, Cytotoxicity, Lung cancer, Apoptosis, Protein expression.

\section{INTRODUCTION}

Cancer is the subsequent driving reason for death on the planet and a significant general medical issue. As alarmed by Globocan, in 2018, 2 million new instances of lung malignant growth accounted for lung diseases. ${ }^{1}$

Lung carcinoma, indistinctively diagnosed in both male and female and even in smokers and non-smokers. The caused though was rooted due to tobacco consumption but it was also found to occur genetically. A combination of intrinsic factors and exposure to environmental carcinogens is perhaps involved in the pathogenesis of lung cancer. The distinctive strategy of diagnostic evaluation has three simultaneous steps viz., tissue diagnosis, staging and functional evaluation and all of which invariably affect the treatment planning and determination of prognosis. Non-small cell lung cancer patients are suspected and tested for presence of various mutations, which, if present, can be treated with new targeted molecular therapies. ${ }^{2}$ The improvement of treatments to battle against seriously increasing tumors is extremely troublesome. Various medicines are accessible for malignant growth treatment however they are confined by the absence of particularity and portion restricting poisonousness. Discovering helpful medications for the treatment of various sorts of malignancy is a test. Nonetheless, most secure strategies are of significance for the mix of controlled discharge, showing focused on conveyance, less destructive and extremely viable. ${ }^{3}$

The utilization of shallot (Allium ascalonicum) in customary medication dates to back to several centuries. Allium species has the potency in controlling cancer and it has the ability to suppress DNA adduct formation, trigger drug metabolizing enzymes responsible for detoxification of carcinogen agents and induction of apoptosis. ${ }^{4}$ In vitro and in vivo studies revealed that they possess has reductive effect on tumour sizes by
Submission Date: 24-08-2020; Revision Date: 08-10-2020; Accepted Date: 03-05-2021

DOI: 10.5530/ijper.55.2.95 Correspondence: Prof. KS Santhy Department of Zoology, School of BioSciences, Avinashilingam Institute of Higher Education for Women, Coimbatore-641 043, Tamil Nadu, INDIA. Phone no: +91-944439960 Email id: santhyanandan@ gmail.com

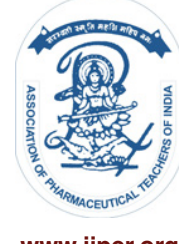

www.ijper.org 
leading apoptotic cancer cell death. Active molecules in allium are also found to function as antioxidant agents in in vitro cell culture models. ${ }^{5}$

Indeed, significant pharmacological properties such as cancer prevention, calming, anti-microbial, antiviral and anti-proliferative potential have been credited to Allicin. Likewise, it has been accounted for that allicin represses malignancy cells and instigates apoptosis by means of caspase-ward and caspase-autonomous pathways through the improvement of gathering of receptive oxygen species. ${ }^{6}$ To be sure, examinations has exhibited that allicin executes malignancy cells and instigates apoptosis in a few disease cell lines, just as hepatocarcinoma and lung malignancy. ${ }^{7}$

Combined utilization of allicin and cisplatin or carboplatin brought about improved development inhibitory impact on SW1736 and HTH7 cells. Moreover, allicin has been accounted for to hinder human renal clear cell carcinoma by means of concealment of the HIF pathway. Besides, allicin hindered the multiplication of human mammary (MCF-7), endometrial and colon (HT-29) malignancy cells. ${ }^{8}$ Fascinating, allicin can animate the invulnerable framework to deliver some bioactive anticancer elements which hinder tumor cells and can likewise invigorate the arrival of numerous cytokines which improve the resistant framework. ${ }^{9}$ Allicin, an organo-sulfur compound, chokes malignant growth development in vitro in lung disease, hepatocellular carcinoma, melanoma, colorectal adenocarcinoma. ${ }^{10,11}$ and glioma cells. ${ }^{12}$ In the present study, the growth inhibitory and apoptotic induction efficacy of allicin was demonstrated in A549 human lung cancer cell lines. Further, the potential cellular inhibitory mechanism of allicin in the selected cancer lines and apoptotic protein expression studies was also investigated.

\section{MATERIALS AND METHODS}

\section{Cell culture}

The Human lung cancer cells (A549) were procured from the National Centre for Cell Sciences (NCCS), Pune, India. Cells were maintained in DMEM supplemented with $2 \mathrm{mM}$ l-glutamine and balanced salt solution (BSS) adjusted to contain $1.5 \mathrm{~g} / \mathrm{L}$ glucose, $1.5 \mathrm{~g} / \mathrm{L} \mathrm{Na}_{2} \mathrm{CO}_{3}, 1 \mathrm{mM}$ sodium pyruvate, $0.1 \mathrm{mM}$ nonessential amino acids, $2 \mathrm{mM}$ l-glutamine, $10 \mathrm{mM}$ HEPES and 10\% foetal bovine serum (GIBCO, USA). Penicillin and streptomycin $(100 \mathrm{IU} / 100 \mu \mathrm{g})$ were adjusted to $1 \mathrm{~mL} / \mathrm{L}$. The cells were maintained at 5\% $\mathrm{CO}_{2}$. Allicin was purchased from Shanghai Harvest Pharmaceutical
Co., Ltd. (Shanghai, China). The purity of allicin used in the experiments was $\geq 90 \%$.

\section{Evaluation of cytotoxicity}

An MTT [3-(4,5-dimethylthiazol-2-yl)-2,5-diphenyltetrazolium bromide, Hi-Media) assay was done to evaluate the inhibitory concentration $\left(\mathrm{IC}_{50}\right)$. The A549 cells were grown $\left(1 \times 10^{4}\right.$ cells / well $)$ in a 96 -well plate for $48 \mathrm{~h}$ to get $70 \%$ confluence of the cells. The medium was substituted with fresh medium containing serially diluted allicin and paclitaxel and the cells were further incubated for $48 \mathrm{~h}$. The culture medium was removed and $100 \mu \mathrm{L}$ of the MTT solution was added to each well and incubated at $37^{\circ} \mathrm{C}$ for $4 \mathrm{~h}$. Then the supernatant was removed, $50 \mu \mathrm{L}$ of DMSO was added to each well and incubated for $10 \mathrm{~min}$ to solubilize the formazan crystals. Using an ELISA multi-well plate reader, the optical density was measured at $620 \mathrm{~nm}$. The results were used to calculate the percentage of viability as given by the following formula.

$\%$ of Viability $=$ OD value of experimental sample/ OD value of experimental control $\times 100$

\section{Morphological study}

The selected human lung cancer cells were allowed to grow on the cover slips $\left(1 \times 10^{5}\right.$ cells/cover slip), incubated with allicin and paclitaxel at different concentrations and fixed using an ethanol: acetic acid solution $(3: 1, \mathrm{v} / \mathrm{v})$. Subsequently, morphological analysis was carried out by mounting the cover slips gently on glass slides. The cells were further analysed to detect morphological changes using Nikon bright field inverted light microscope at 40x magnification.

\section{Fluorescence microscopic analysis of apoptotic cell death}

One micro litre of the dye mixture $(100 \mathrm{mg} / \mathrm{mL}$ Acridine Orange (AO) and $100 \mathrm{mg} / \mathrm{mL}$ Ethidium Bromide (Et $\mathrm{Br}$ ) in distilled water was mixed with $0.9 \mathrm{~mL}$ of the cell suspension $\left(1 \times 10^{5}\right.$ cells $\left./ \mathrm{mL}\right)$ on clean microscope cover slips. The pre-treated cancer cells with different concentrations of allicin and paclitaxel were collected, washed with phosphate buffered saline (PBS) $(\mathrm{pH}$ 7.2) and stained with $10 \mu \mathrm{L}$ of $\mathrm{AO} / \mathrm{EtBr}$. After incubation for $2 \mathrm{~min}$, the cells were washed twice with PBS and visualized under a fluorescence microscope (Nikon Eclipse, Inc, Japan) at 40x magnification, with a 480nm excitation filter. Besides, the cells were placed on a glass coverslip in a six-well plate and treated with different concentrations of allicin and paclitaxel for 24 h. The treated cells were fixed with methanol: acetic acid $(3: 1, v / v)$ and then washed with PBS. The cells were subsequently stained with $10 \mu \mathrm{L}$ of DAPI for 20 
min in the dark and were observed under fluorescence microscope (Nikon Eclipse, Inc, Japan).

\section{Propidium iodide staining}

The cells were seeded $\left(1 \times 10^{6}\right.$ cells $\left./ \mathrm{ml}\right)$ into wells containing DMEM medium with tested compounds. After $24 \mathrm{~h}$ incubation at $37^{\circ} \mathrm{C}$ in a $\mathrm{CO}_{2}$ incubator, cells were harvested and fixed with methanol and acetic acid fixative. Later cells were smeared over clean dry and nongreasy glass slides. In brief, smeared cells were stained with Ethidium bromide $(10 \mathrm{mg} / \mathrm{ml})$ solution. The cells were immediately washed with phosphate buffer and observed under (Nikon Eclipse, Inc, Japan) fluorescent microscope to analyze the nuclear fragmentation.

\section{Detection of apoptosis by flow cytometry}

A549 cells $\left(1 \times 10^{5}\right)$ were seeded in a six-well plate. After $24 \mathrm{~h}$ incubation at $37^{\circ} \mathrm{C}\left(5 \% \mathrm{CO}_{2}\right)$, the medium was changed with or without (control) allicin (2.5, 5 and $10 \mu \mathrm{g} / \mathrm{mL}$ ). After $24 \mathrm{~h}$ incubation, the cells were harvested with trypsin, washed with PBS, suspended in binding buffer and stained using Annexin V-FITC and Propidium Iodide. Later, they were incubated in the dark for $15 \mathrm{~min}$ at room temperature. Furthermore, after the addition of binding buffer, flow cytometry was performed in duplicate with a BD FACS Verse flow cytometer. From each sample, 10,000 events were collected and the fluorescent signal intensity was recorded and analysed by Cell Quest and Modifit.

\section{Cell cycle analysis}

The A549 cells $\left(1 \times 10^{5}\right)$ were seeded in a 6-well plate. After incubating for $24 \mathrm{hrs}$ at $37^{\circ} \mathrm{C}\left(5 \% \mathrm{CO}_{2}\right)$, the medium was replaced with allicin and paclitaxel solution. Cells devoid of allicin and paclitaxel served as experimental control. After the incubation period (24 hrs), cells were harvested with trypsin, washed by PBS, fixed in $70 \%$ ethanol and stored at $-20^{\circ} \mathrm{C}$ for $1 \mathrm{~h}$. The nuclear DNA of the cells was stained with Propidium Iodide. Flow cytometry was performed using a BD FACS flow cytometer. The intensity of fluorescence signal was monitored and analyzed utilizing Cell Quest and Modifit.

\section{Western blotting}

Western blotting was performed to analyse the regulation of apoptotic and anti-apoptotic proteins in the treated and untreated cells. A549 cells $\left(1.5 \times 10^{6}\right)$ were seeded onto $100 \mathrm{~mm}$ culture dishes in the presence or absence of the allicin and paclitaxel and were treated for $24 \mathrm{~h}$. The medium was removed and the cells were washed with PBS (0.01 M, pH 7.2) several times. Following the removal of the supernatant, the cells were lysed with lysis buffer ( $0.1 \mathrm{~mL}$ of lysis buffer for each plate) for 20 min. The supernatants were collected by centrifugation at $10,000 \mathrm{~g}$ for $5 \mathrm{~min}$ at $4^{\circ} \mathrm{C}$ and were used as cell protein extracts. An identical amount of protein from each sample concentration was applied to $12 \%$ SDSpolyacrylamide gel electrophoresis. The proteins were transferred onto a nitrocellulose membrane and then blocked for $1 \mathrm{~h}$ using 10\% skimmed milk in water. After washing thrice in PBS containing 0.1\% Tween20 , primary antibodies against Caspase 3 , Cytochrome c, Bcl-2 and $\beta$-actin were added at a v/v ratio of 1:1000. After incubation overnight at $4^{\circ} \mathrm{C}$, the primary antibodies were washed away and the secondary antibodies were added and incubated for $1 \mathrm{~h}$ at room temperature. Then protein bands were visualized.

\section{RT-PCR analysis}

The A549 cells were treated with various concentrations of allicin and paclitaxel. After 24 hrs treatment, the medium was completely removed from the flask. TriZol reagent was used to isolate total RNA and the RNA was reverse transcribed. The cDNA was isolated by using the cDNA synthesis kit and amplified according to the instruction. The RT-PCR for apoptotic genes were performed in $20 \mu \mathrm{L}$ reaction mixture containing random primer pairs (forward and reverse $0.5 \mu \mathrm{L}+0.5 \mu \mathrm{L}$ ) 1.0 $\mu \mathrm{L}, 10 \mathrm{X}$ reaction buffer containing master mix $(25$ $\mathrm{mM} / 1 \mathrm{MgCl}_{2}, 10 \mathrm{mM} / 1 \mathrm{dNTPs}$, Taq polymerase $2.5 \mathrm{U}$ ) $10 \mu \mathrm{l}$, cDNA as template $2 \mu \mathrm{l}$ and remaining volume is nuclease free $\mathrm{dH}_{2} \mathrm{O} 7 \mu$ l. Amplification cycles consisted of denaturation at $94^{\circ} \mathrm{C}$ for $1 \mathrm{~min}$, primer annealing at $55^{\circ} \mathrm{C}$ for $40 \mathrm{sec}$ and extension at $72^{\circ} \mathrm{C}$ or I min, for a total of 32 cycles followed by final extension at $72^{\circ} \mathrm{C}$ for $10 \mathrm{~min}$.

\section{Statistical analysis}

The data were analysed using the SPSS software. The results were presented as mean \pm SD. Differences among the multiple groups were analysed by conducting one-way analysis of variance (ANOVA). $P<.05$ was considered statistically significant.

\section{RESULTS}

\section{MTT Assay}

In this investigation, we evaluated the allicin, a characteristic compound with high potential as an adjuvant operator. The cytotoxic activity of Allicin in A549 lung carcinoma cells were examined using MTT assay. As shown in Figure 1, the level of viable cells was reduced on treatment of Allicin with increasing concentrations after $24 \mathrm{~h}$ and $48 \mathrm{~h}$. In accordance to it, 
the experimental results indicated that the compounds inhibited cell proliferation in a dose dependent manner (Figure 1). The $\mathrm{IC}_{50}$ value of allicin in A549 cells was determined as $28 \pm 0.5 \mu \mathrm{M}$, where $* P<.05$ was considered statistically significant. The cytotoxicity uncovered the strong anticancer potency of Allicin against A549 cells relying upon the fact increased concentration leading to cell death in A549 cells.

\section{Cell Morphology}

The morphological change in A549 cells after treatment with allicin and paclitaxel for $24 \mathrm{~h}$ is shown in Figure 2. The transformation in the morphology of treated cells can be noted in dose dependent manner. Cytotoxicity increased with increasing concentration, Allicin and paclitaxel exhibited marked cell shrinkage, minimizing the cell volume and showed decrease in number of viable cells.

\section{PI Staining}

Propidium iodide is a fluorescent DNA binding dye which is used to examine the morphological changes in nuclei apoptotic. Nuclear fragmentation is a characteristic feature of cells undergoing apoptotic

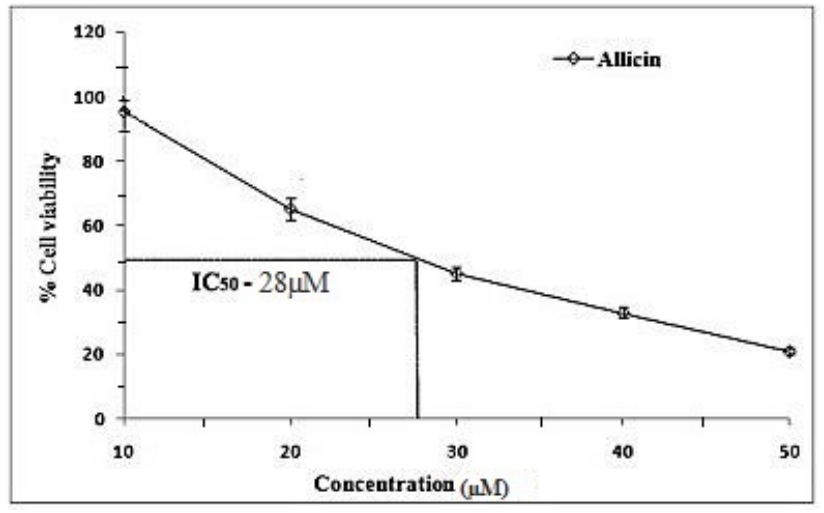

Figure 1: Cytotoxicity of allicin in A549 cells by MTT assay. The $\mathrm{IC}_{50}$ value of allicin in A549 cells was determined as $28 \pm$ $0.5 \mu \mathrm{M}$, where ${ }^{*} P<0.5$ was considered statistically significant.
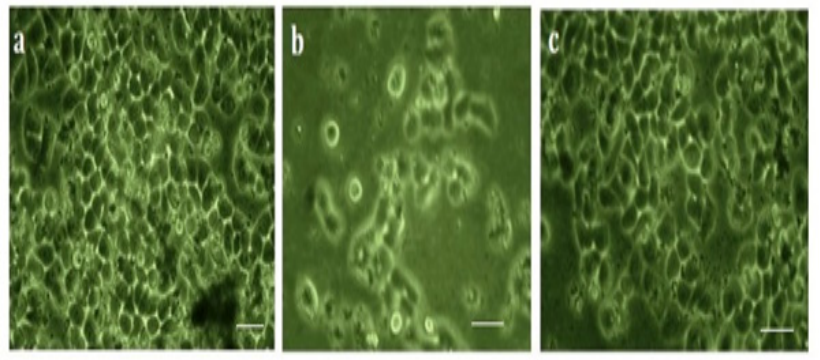

Figure 2: Morphological changes in in A549 cells (a) control (b) paclitaxel (c) allicin. Scale bars with magnification up to 40X. death cells. Allicin and paclitaxel treated and untreated A549 cells were analysed for its nuclear morphology under fluorescence microscopy in the staining of the nuclear specific dye Propidium iodide. It was noted, that there was a notable difference between control and allicin and/or paclitaxel treated cells. After treatment with allicin, there were more apoptotic cells with marked cytological changes. The nucleus was condensed and divided to form apoptotic bodies upon treatment (Figure 3) whereas, paclitaxel also showed competitive changes to the drug, however, the control cells did not show any fragmentation in nucleus.

\section{Fluorescence microscopic analysis of nuclear fragmentation- AO/EtBr and DAPI}

Dual acridine orange/ethidium bromide ( $\mathrm{AO} / \mathrm{Et}$ $\mathrm{Br}$ ) fluorescent staining is used to identify apoptosisassociated changes in cells and to discriminate between different stages of apoptosis The fluorescence microscopic analysis was carried out to confirm and further evaluate the apoptotic activity of allicin and paclitaxel on cancer cells. The images of A549 lung cancer cells control, paclitaxel and allicin are given in Figure 4. The images clearly established that the
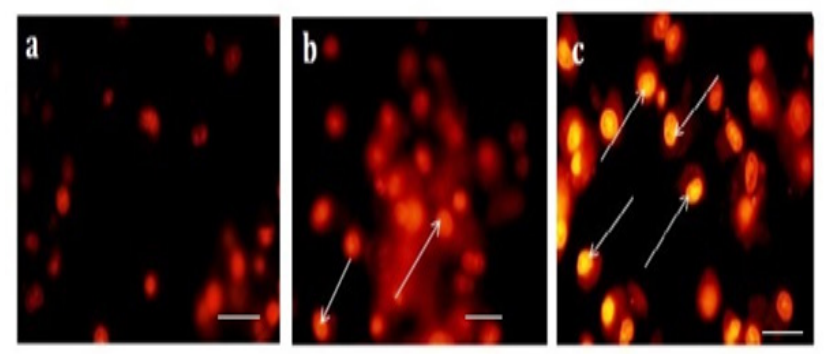

Figure 3: Apoptotic analyses and determination of dead and live cells on treatment with allicin and paclitaxel in A549 cells by PI staining in the figure (a) control (b) paclitaxel (c) allicin and arrows indicate the nuclear changes. Scale bars with magnification up to $40 \mathrm{X}$.
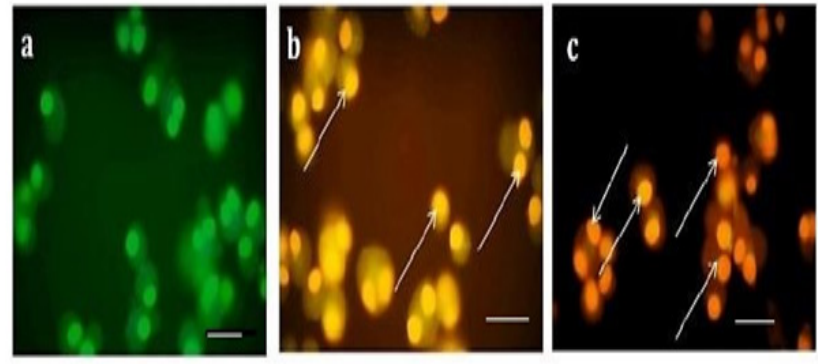

Figure 4: Apoptotic analysis and determination of dead and live cells on treatment with allicin and paclitaxel in A549 cells by $\mathrm{AO} / \mathrm{EtBr}$ staining. In the figure (a) control (b) paclitaxel (c) allicin and arrows indicate the pro and late apoptotic cells. Scale bars with magnification up to $40 \mathrm{X}$. 
untreated cells (Figure 4a) did not show any significant change in nucleus. Whereas, Figure $4 \mathrm{~b}$ and $4 \mathrm{c}$ clearly showed the transformation of green coloured cells to orange/red colour, which was due to the induction of apoptosis and the nuclear condensation effect endorsed to the action of drugs group. Furthermore, to confirm the nuclear fragmentation effect of allicin on the cancer cells, DAPI staining was performed.

The effect of allicin and / or paclitaxel on the cell cycle of the lung cancer cell line was studied using DAPI staining. The results showed that control/ untreated cells were distributed across all the phases of the conventional cell cycle, whereas, in all the other treatment groups, the cells were locked in G2 phase. This showed that the allicin, as well as paclitaxel, caused increased apoptosis which caused cell cycle arrest. Fluorescence microscopic images of the cells stained with DAPI after $24 \mathrm{~h}$ in presence of allicinand paclitaxel are shown in Figure 5. It could be seen that the untreated cells display only a feeble excitation of the fluorescent light owing to the presence of intact nucleus Figure 5a; however, the allicin and paclitaxel treated cells (Figure 5, b-c) revealed bright shades, indicating the formation of condensed chromatins and nuclear fragmentations.
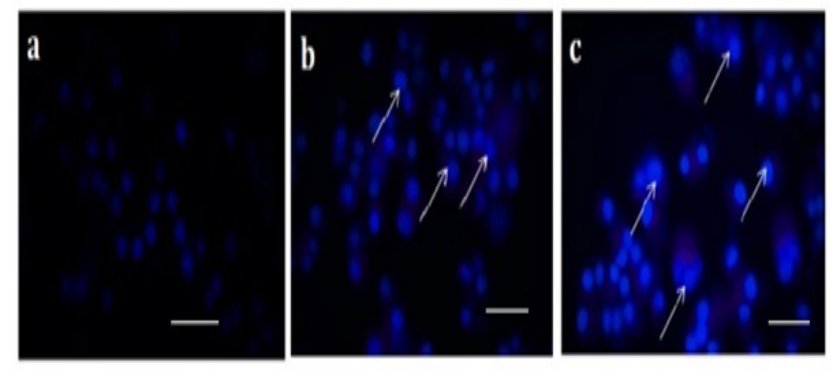

Figure 5: Apoptotic analysis and determination of dead and live cells on treatment with allicin and paclitaxel in A549 cells by DAPI staining. In the figure (a) control (b) paclitaxel (c) allicin. Scale bars with magnification up to $40 \mathrm{X}$.
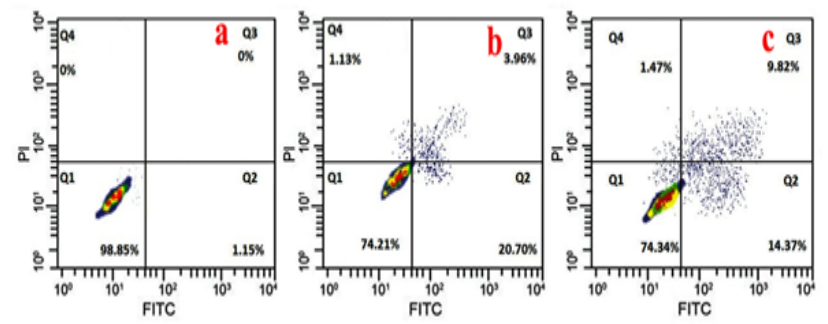

Figure 6: Effect apoptosis, DNA damage, cell proliferation and cell cycle analysis in A549 cells using flow cytometry. In the figure, (a) control (b) allicin (c) paclitaxel. In the panel, I, II, III and IV refer to live cells, pro-apoptotic cells, late apoptotic cells and necrotic cells respectively.
Thus, from the results of MT'T assay and fluorescence microscopic analysis, we report that Allicin was effective in controlling the growth of cancer cells. All the above findings are very significant observations because they evidenced that Allicin clearly discriminated a targeted action on cancerous cells through the selective recognition of a specific component expressed by the cancer cells alone.

\section{Apoptosis -Annexin-V/FITC}

The effect of Allicin on apoptosis was evaluated by performing Annexin V/PI staining and FACS analysis. The histograms (shown in Figure 6) demonstrated the distribution of the cells as follows: lower left quadrant cells (I) denote the live cells; the lower right quadrant cells (II) represent the early apoptotic cells; the upper right quadrant cells (III) symbolize the late apoptotic cells; and the upper left quadrant cells (IV) signify the necrotic cells respectively. The histogram depicted presence of many viable cells and only few early apoptotic, late apoptotic and necrotic cells in the control. However, a dose-dependent treatment of Allicin resulted in a gradual shifting of the live cells to early apoptotic, late apoptotic and necrotic cells. Thus, the result specified augmentation in the effect of allicin with increasing concentration

\section{Cell cycle analysis}

The cell cycle arresting potency of allicin and paclitaxel was studied by flow cytometry analysis by treating the cells at various concentrations. It is apparent (as in Figure 7) that the Allicin was capable of impairing the cell cycle at DNA synthetic phases. In control, the cells accumulated in the G0/G1 and G2/M phase. The quantity of cells at the G0/G1-phase vividly diminished after treating with various concentrations of allicin and paclitaxel in the selected lung cancer cells. Evidently, in contrast with the control cells, the DNA duplication stage was arrested in the treated cells. The outcomes recommend that the counter proliferative impact of allicinis prevalently because of the enlistment of cell cycle arrest, especially in the DNA synthesis stage.

\section{Effect of Allicin on the regulation of protein expression}

The complete process of apoptosis is conventionally intervened by different proteins. To distinguish the apoptotic pathway in which Allicin and paclitaxel prompted cell death, the expression levels of different apoptotic proteins including Caspase-3, p53, Cytochrome c, Bcl-2 and the internal protein marker $\beta$-actin were checked (Figure 8A), The relative protein fold change is expressed in mean \pm S.E (Figure $8 \mathrm{~B}$ ). The 
results of the current investigation showed that the allicin fraction up regulated multiple genes involved in the pathways of adhesion, cell cycle control, apoptosis and signal transduction. It also profoundly influenced angiogenesis and metastasis, wherein some genes were also down regulated. Our findings demonstrated the up regulation of different proteins including Caspase-3, p53, Cytochrome c, in the Allicin treated cells in a dose dependent manner and a critical down-regulation in the expression of bcl-2. In any case, the interior control protein actin did not show any change all through the analysis.

\section{Effect of Allicin on apoptotic gene expression}

Bax is the pro-apoptotic gene that induces the release of cytochrome $\mathrm{c}$ and leads to the caspase activation in the apoptotic pathway. Along with Cytochrome c, Caspase-3, Bcl-2 and $\beta$-actin were also selected for gene expression studies in Human lung cancer cells. The results showed that in the control group there were no significant expression patterns of selected genes. Whereas the allicin treated A549 cells, selected pro-apoptotic genes namely Cytochrome c, Caspase 3 , showed up-regulatory pattern and down regulation of anti-apoptotic gene Bcl-2 was observed (Figure 9A) and the densitogram of expression is shown in Figure
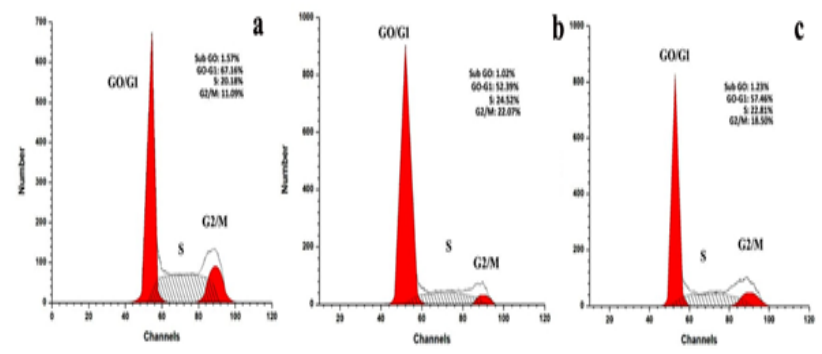

Figure 7: Determination of cell cycle analysis in A549 cells by flow cytometry. In the figure, (a) control (b) allicin (c) paclitaxel.
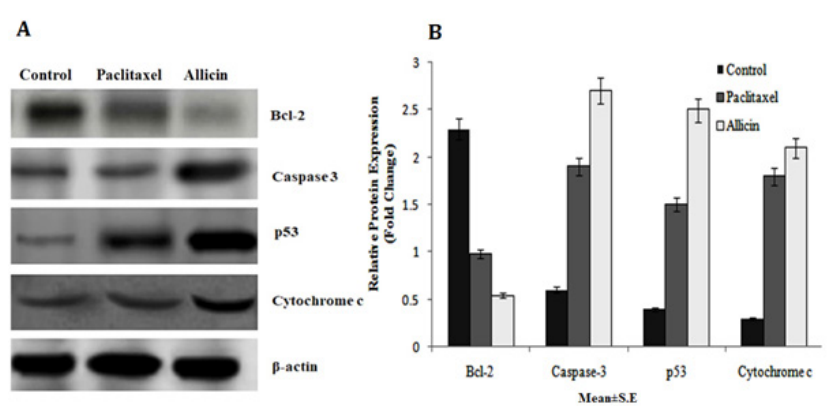

Figure 8: A). Differential expression of selected proteins in treated A549 cells using western blot. B). Densitometry analysis of protein expression represented as Mean \pm S.E. In the figure, (a) control (b) allicin (c) paclitaxel.
$9 \mathrm{~B}$, where relative protein fold change is expressed in mean \pm S.E.

\section{DISCUSSION}

Plethora of research findings are accounted on exploring the traditional medicine for the present challenging diseases. In the present study, the allicin, effective natural compound from the Allium ascalonicum herb, exhibited apoptosis. Generally, allicin is considered as non-toxic in normal cells. ${ }^{12}$ While, similar studies have reported that, allicin $24 \mathrm{~h}$ treatment was demonstrated to be effective against lung, breast and colon cancer growth. Also, Allicin can hinder cancer cell growth and more precisely halt relocation and expansion of lung adenocarcinoma after $24 \mathrm{~h}$ treatment. ${ }^{13,14}$

The organic impacts of Allicin are credited to the thiol and sulphurmoities. The dynamic organosulfur compound was strong in disturbing the microtubules by interfering with tubulin polymerization. By hindering the microtubule polymerization, Allicin repressed cell polarization and movement and diminished cell division. Its anti-proliferative activity was decoded against human cervical malignancy cells, cholangio carcinoma, lung adenocarcinoma, renal cell carcinoma and ovarian cancer. ${ }^{15}$ Comparatively, paclitaxel showed increased inhibitory impact articulated in the morphological moieties. Specifically the cytoskeleton and the cell shape were distorted. Bortner et al. ${ }^{16}$ reported the similar morphological changes were seen in SK-MES-1 cells with substantial decline in the apoptotic volume after co-treatment. Also, the atomic harm affirmed the inception of apoptosis. The apoptotic volume decline was accounted for to be an indication of cell demise that happens through apoptosis.

Mohankumar et al. ${ }^{17}$ determined the cytotoxicity of an ortho-hydroxy substituted analog of curcumin (BDMC-A) in MCF 7 breast cancer cells and revealed
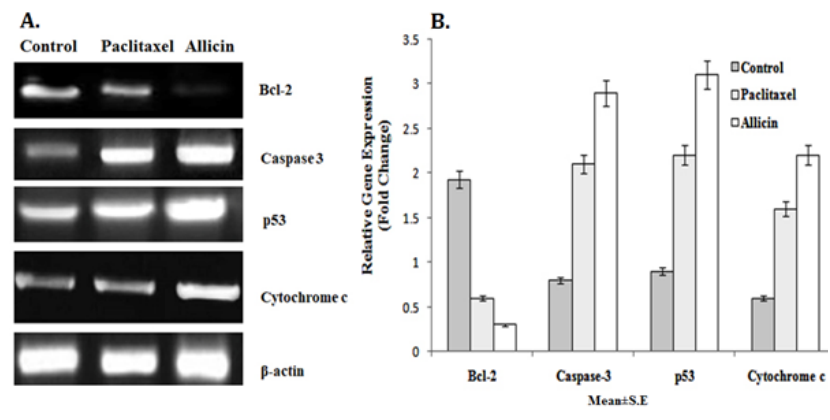

Figure 9: A). Differential expression of selected protein in treated A549 cells using RT- PCR. B). Densitometry analysis of protein expression represented as Mean \pm S.E. In the figure, (a) control (b) allicin (c) paclitaxel. 
that PI was taken up by treated cells and fragmented nuclei were observed in higher numbers than untreated cells. Studies on the cytotoxic effects of nimbolide, a limonoid present in leaves and flowers of the neem tree (Azadiracbta indica) on human breast cancer cells MCF-7 and MDA-MB-231 by AO / EtBr dual staining showed significant morphological changes characteristic of apoptotic cells, such as cell shrinkage and reduced cell density. ${ }^{18} \mathrm{It}$ is evident from the previous studies that $\mathrm{AO}$ dye was unable to permeate the intact cell membrane, which stains live cells with bright green fluorescence, while $\mathrm{EtBr}$ can only enter the membrane of damaged cells and stains the nuclei orange.

While similar studies have reported the potency of natural compounds in cell cycle arrest. In MCF-7 breast cancer cells, Koenimbin, a natural dietary compound of Murraya koenigii $(\mathrm{L})$ induced the cell cycle arrest significantly at sub-G0 phase. ${ }^{19}$ While Wei et al. ${ }^{20}$ iterated that n-butanol fraction from the extract of Alocasia cucullata increased the cell ratio at G0/G1 phase in gastric cancer cell line (MGC-803). In parallel, methanolic extract of fruits and barks of Zanthozyllum heitrii, significantly caused cell cycle arrest at G0/G1 phase in human leukemia HL-60 cells in a dose dependent manner. ${ }^{21}$

The selected allicin and paclitaxel treated cells in the G2/M period of the cell cycle were unable to frame a normal mitotic mechanical assembly. Therefore, allicin intervened with cell process through the apoptotic induction and arrested the cell cycle. Standard anticancer medications functions by means of a microtubule destabilizing component, by means of authoritative to the tubulin protein and preventing the cell from isolating its chromosomes during the metaphase; the cell at that point experiences apoptosis.

The observation made in the present study was in adhesion with the other research reports, Extract of Neem leaf enhanced apoptosis by up regulating proapoptotic genes in N-methyl-N nitrosourea-induced mammary cancer in rat in vivo. ${ }^{22}$ While the active peptides extracted from the non-digestible fraction of Phaseolus vulgaris caused a differential gene expression in two human colorectal cancer cell lines, resulting in the upregulation of apoptosis. ${ }^{23}$

\section{CONCLUSION}

To conclude, all these experimental observations and reports further strengthen the fact that Allicin possesses efficient anti-proliferative activity against lung cancer cells. Further, our results showed that allicin significantly induced apoptotic cell death leading to arrest cell cycle in $G_{2} / M$ phase. To put in a nut shell, our findings are pilot evidences which highlight and indicate the potency of allicin as a future candidate for the development of lung cancer chemotherapeutic agent, which can induce targeted cell death in cancer cells.

\section{ACKNOWLEDGEMENT}

The authors gratefully acknowledge and thank the institution for providing the research facilities and infrastructural support to carry out the research work.

\section{CONFLICT OF INTEREST}

The authors declare no conflict of interest.

\section{ABBREVIATIONS}

IC $_{50}$ : Inhibitory Concentration; RT-PCR: Reverse transcription polymerase chain reaction; DMEM: Dulbecco's modified eagle's medium; HEPES: 4-(2-hydroxyethyl)-1-piperazineethane sulfonic acid; MTT: 3-(4,5-dimethylthiazol-2-yl)-2,5diphenyltetrazolium bromide; ELISA: Enzyme-linked immunosorbent assay; AO: Acridine Orange; Et Br: Ethidium Bromide; $\mathbf{C O}_{2}$ : Incubator Carbon dioxide incubator; FITC: Fluorescein isothiocyanate; PBS: Phosphate Buffer Sulphate; DAPI: 4',6-Diamidino-2Phenylindole Bcl-2 B-cell lymphoma 2.

\section{REFERENCES}

1. Siegel RL, Torre LA, Soerjomataram I, Hayes RB, Bray F, Weber TK, et al. Global patterns and trends in colorectal cancer incidence in young adults. Gut. 2019;68(12):2179-85.

2. Omar EA. The outline of prognosis and new advances in diagnosis of oral squamous cell carcinoma (OSCC): Review of the literature. Journal of Oral Oncology. 2013.

3. Kleinstreuer C, Feng Y, Childress E. Drug-targeting methodologies with applications: A review. World Journal of Clinical Cases. 2014;2(12):742.

4. Nouroz F, Mehboob M, Noreen S, Zaidi F, Mobin T. A review on anticancer activities of garlic (Allium sativum L.). Middle-East Journal of Scientific Research. 2015;23(6):1145-51.

5. Mnayer D, Fabiano-Tixier AS, Petitcolas E, Hamieh T, Nehme N, Ferrant C, et al. Chemical composition, antibacterial and antioxidant activities of six essentials oils from the Alliaceae family. Molecules. 2014;19(12):20034-53.

6. Belmokhtar CA, Hillion J, Ségal-Bendirdjian E. Staurosporine induces apoptosis through both caspase-dependent and caspase-independent mechanisms. Oncogene. 2001;20(26):3354-62.

7. Li T, Shi HY, Hua YX, Gao C, Xia Q, Yang G, et al. Effects of allicin on the proliferation and cell cycle of chondrocytes. International Journal of Clinical and Experimental Pathology. 2015;8(10):12525.

8. Longley DB, Harkin DP, Johnston PG. 5-fluorouracil: Mechanisms of action and clinical strategies. Nature Reviews Cancer. 2003;3(5):330-8.

9. Lichota A, Gwozdzinski K. Anticancer activity of natural compounds from plant and marine environment. International Journal of Molecular Sciences. 2018;19(11):3533.

10. Tsubura A, Lai YC, Kuwata M, Uehara N, Yoshizawa K. Anticancer effects of garlic and garlic-derived compounds for breast cancer control. Anti-Cancer Agents in Medicinal Chemistry (Formerly Current Medicinal Chemistry-AntiCancer Agents). 2011;11(3):249-53. 
11. Rajput S, Mandal M. Antitumor promoting potential of selected phytochemicals derived from spices: A review. European Journal of Cancer Prevention. 2012;21(2):205-15.

12. Li C, Jing H, Ma G, Liang P. Allicin induces apoptosis through activation of both intrinsic and extrinsic pathways in glioma cells. Molecular Medicine Reports. 2018;17(4):5976-81.

13. Bat-Chen W, Golan T, Peri I, Ludmer Z, Schwartz B. Allicin purified from fresh garlic cloves induces apoptosis in colon cancer cells via Nrf2. Nutrition and Cancer. 2010;62(7):947-57.

14. Chu YL, Ho CT, Chung JG, Rajasekaran R, Sheen LY. Allicin induces p53-mediated autophagy in Hep G2 human liver cancer cells. Journal of Agricultural and Food Chemistry. 2012;60(34):8363-71.

15. Wang JH, Nao JF, Zhang M, He P. 20 (s)-ginsenoside Rg3 promotes apoptosis in human ovarian cancer HO-8910 cells through PI3K/Akt and XIAP pathways. Tumor Biology. 2014;35(12):11985-94.

16. Bortner CD, Cidlowski JA. Cell shrinkage and monovalent cation fluxes: Role in apoptosis. Archives of Biochemistry and Biophysics. 2007;462(2):176-88.

17. Mohankumar K, Pajaniradje S, Sridharan S, Singh VK, Ronsard L, Banerjea $\mathrm{AC}$, et al. Mechanism of apoptotic induction in human breast cancer cell, MCF-7, by an analog of curcumin in comparison with curcumin-an in vitro and in silico approach. Chemico-biological Interactions. 2014;210:51-63.

18. Elumalai P, Gunadharini DN, Senthilkumar K, Banudevi S, Arunkumar R, Benson CS, Sharmila G, Arunakaran J. Induction of apoptosis in human breast cancer cells by nimbolide through extrinsic and intrinsic pathway. Toxicology letters. 2012;215(2):131-42.

19. Ahmadipour F, Noordin MI, Syam MAA, Paydar M, Looi CY, Keong YS, et al. Koenimbin, a natural dietary compound of Murraya koenigii $(\mathrm{L})$ Spreng: inhibition of MCF7 breast cancer cells and targeting of derived MCF7 breast cancer stem cells (CD44+/CD24-/low): An in vitro study. Drug Design, Development and Therapy. 2015;9:1193.

20. Wei P, Zhiyu C, Xu T, Xiangwei Z. Antitumor effect and apoptosis induction of Alocasia cucullata (Lour.) G. Don in human gastric cancer cells in vitro and in vivo. BMC Complementary and Alternative Medicine. 2015;15(1):1-1.

21. Pieme CA, Santosh GK, Tekwu EM, Askun T, Aydeniz H, Ngogang JY, et al. Fruits and barks extracts of Zanthozyllum heitzii a spice from Cameroon induce mitochondrial dependent apoptosis and Go/G1 phase arrest in human leukemia HL-60 cells. Biological Research. 2014;47(1):54.

22. Arumugam A, Agullo P, Boopalan T, Nandy S, Lopez R, Gutierrez C, et al. Neem leaf extract inhibits mammary carcinogenesis by altering cell proliferation, apoptosis and angiogenesis. Cancer Biology and Therapy. 2014;15(1):26-34.

23. Vital DA, Loarca-Piña G, Dia VP, DeMejía EG. Peptides extracted from common bean (Phaseolus vulgaris L.) non-digestible fraction caused differential gene expression of HCT116 and RKO human colorectal cancer cells. Food Research International. 2014;62:193-204.

\section{PICTORIAL ABSTRACT}

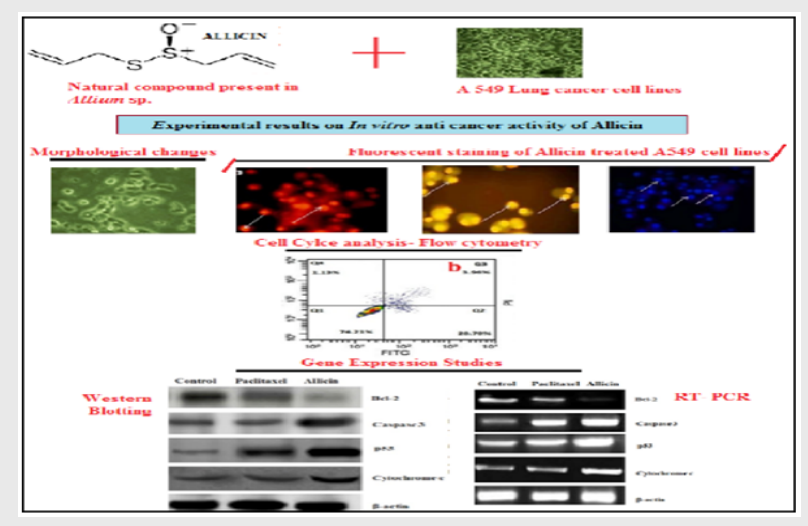

\section{SUMMARY}

Allicin exhibited multifaceted chemotherapeutic effect by affecting cell-cycle arrest, apoptosis, reduction cell development, angiogenesis and proteasome activity. Our outcomes of the study demonstrated that the candidate allicin, had significant anticancer potential against human lung cancer cells.

\section{About Authors}

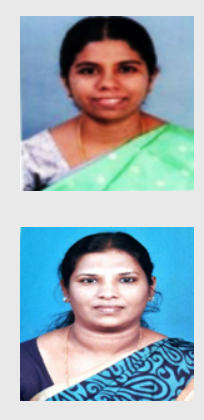

Dr. K.S. Santhy is currently working as a Professor in the Department of Zoology, Avinashilingam Institute for Home Science and Higher Education for Women, Coimbatore. She holds an academic experience over 18 years in the field of Cancer Biology and Phytotherapeutics.

Zeenath VMH is currently doing Ph.D., Department of Zoology, Avinashilingam Institute for Home Science and Higher Education for Women, Coimbatore.

Cite this article: Zeenath VMH, Santhy KS. Antiproliferative and Apoptotic Induction of Allicin in Human Lung Cancer Cell Lines. Indian J of Pharmaceutical Education and Research. 2021;55(2):566-73. 